\title{
Media, multilingualism and language policing: an introduction
}

\author{
Jan Blommaert · Helen Kelly-Holmes · Pia Lane • \\ Sirpa Leppänen · Máiréad Moriarty • \\ Sari Pietikäinen · Arja Piirainen-Marsh
}

Received: 20 April 2009/Accepted: 20 April 2009/Published online: 18 June 2009

(C) The Author(s) 2009. This article is published with open access at Springerlink.com

Michel Foucault (2007:313) describes how, in the seventeenth century, the term "police" was used to describe the rational management of the state, "the set of means by which the state's forces can be increased while preserving the state in good order". This rational management would be effected through the collection and production of knowledge about the people, so as to strengthen the state. Such knowledge would be infinitely detailed, stretching into the smallest corners of human conduct. And the product of policing would be "order". The state, as we know, is just one actor among many regulating language behaviours in contemporary globalised societies. Building on recent critiques of the modernist tradition in language policy (e.g. Shohamy 2006; Ricento 2006; Wright 2004), we argue that Foucault's notion of "police" and "policing" can be fruitfully extended to cover the activities of a wide range of actors, from the state to individuals, over civil society and corporate actors. We propose to use the notion of "policing" in the domain of language in this sense: as the production of "order"-normatively organised and policed conduct - which is infinitely detailed and regulated by a variety of actors.

Our objective in borrowing this concept is to open an actor-centered field of inquiry into what is currently understood in terms of the top-down and bottom-up dichotomy and the continuum of "overt" and "covert" language policies (Shohamy 2006 ) in the domain of media in multilingual contexts. With this in mind, the papers in this volume propose the following conceptual shifts in examining language policy:

1. From 'policy' to the broader field of 'normativity', and so to 'policing'. Multilingual media contexts demonstrate emerging media practices and policing that call into question the concept of language codified in the

\footnotetext{
J. Blommaert $(\bowtie) \cdot$ H. Kelly-Holmes · P. Lane $\cdot$ S. Leppänen · M. Moriarty ·

S. Pietikäinen · A. Piirainen-Marsh

Tilburg University, Tilburg, The Netherlands

e-mail: jan.blommaert@campus.jyu.fi
} 
modernist era (Ricento 2000) in official language policies. These practices can be hard to classify in terms of established dichotomies (e.g. top-down/ bottom-up) and continua (overt-covert).

2. From 'multilingualism', conceptualised as parallel monolingualisms in policy terms, to 'heteroglossia', with an increased emphasis on 'voice' rather than on 'language'. In the mediated environments which we shall address, it is not just language that is policed but also registers, genres and styles, lexis and pronunciation, when it comes to the production of messages, meanings and identities.

3. From a monocentric (or hegemonic) view of the nation-state as the main actor and delineator of language norms, to polycentric multilingual environments that may or may not include national units. For instance, new media (e.g. the internet and computer games) create translocal moments of activity and awareness in otherwise strictly local environments, thus offering multiple forms of allegiance, multiple directions of activity, and multiple orientations to norms.

We focus our analyses on mediating actors in contemporary multilingual, globalised contexts. These actors are located in diverse centres of media production and reception, and engage in contradictory processes of convergence (e.g. the growth in global media products) and divergence (e.g. the growth of minority language media), raising important questions of agency and subjectivity. Further complicating this is the persistence of actors operating within established paradigms and structures of the modernist era in media and language policy, who are in turn challenged by these new actors and processes. The actors of language policing which we examine range from highly institutionalised (macro-level) agents such as the Norwegian Language Council to meso-level institutions such as minority media and internet language training companies, down to the individual media consumer interacting with global entertainment products.

One of the things the papers frequently return to is what we see as 'modernist' responses to 'postmodern' conditions. Fragmentation, plurality and hybridisation, to no small degree enabled and spurred on by mediation and the intervention of a multitude of actors, appear to allow the (re-) emergence of language ideologies stressing uniformity, stability, homogeneity-the key terms of modernism amounting to the denial of hybridity (Bauman and Briggs 2003; Bauman 1986). For instance, we see how internet companies sell a highly essentialised 'American accent' and exclude every form of deviation from its presumed normativity. In this sense, we see that postmodern and globalised environments may contain ideological and practical features that defy or reverse the very essence of these environments, namely, fragmentation, hybridisation, destabilised identities. Language policing, as the papers in this volume show, often plays a major role in such processes.

The production of particular identities, and the struggles involved in that production, are manifest in the first paper in the volume, by Pia Lane. Analysing a debate that raged in the Norwegian media, triggered by an essentialist statement by the director of the Norwegian Language Council, Lane demonstrates how a diversity of actors enters the debate, using the affordances of old and new media, heavily institutionalised ones as well as informal ones. The statement made by the 
director of the Language Council was about the normalcy of 'ethnic Norwegians' in the definition of Norwegianness. This statement was countered by voices arguing for a more diverse, plural and hybridised view of national identity more in tune with the multilingual and multicultural realities of contemporary Norway. Lane also shows how this debate connects with the older problematic of the recognition of national minorities such as the Kven, highlighting the critical role of language in the modernist nation state project. Social categorisations such as 'minority' and 'immigrant' predefine and format the social, cultural and linguistic identities of groups thus described, and national language policies are often dependent on such categorisations. National minorities, for instance, have linguistic rights, while immigrants do not and are thus not included in the multilingual spectre of the state. The capacity of media to enable highly diversified debates in which a plurality of voices can be articulated is not to be underestimated. Such debates often shape and amend the realities of language use (Blommaert 1999), and in the case documented by Lane, we see how the essentialist view from above is challenged by a more realist range of views from below. Issues of language, culture and identity, are thus circulated in a polycentric network of actors, all of whom are in search of 'order'

This theme is recapitulated in the second paper in the volume. Recognising that, often, official language policy and actual use of various linguistic resources are far apart, Kelly-Holmes, Moriarty and Pietikäinen explore the tensions and complementarities between these different dimensions of language policy in three distinct but also comparable minority language media contexts: Basque, Irish and Sámi. In the case of Basque language television, the explicit language policy of the channel ETB-1 is to broadcast in Basque only. In practice this means in the standard variety of the language, Batua, a policy that seems to have impacted on the potential of the channel to fulfil its function as a mechanism of language policy. In 'overt' policy terms, as Shohamy (2006) describes it, commercial radio stations in Ireland operate in an officially bilingual context (Irish and English) and are required as part of their licensing to devote a certain amount of time to Irish language programming. However, the practical implementation of this requirement often undermines explicit policy. In Sámi media, the official language policy is one of Sámi-only, closely linked to the strong language revitalisation discourse in Sámiland. At the same time, however, the actual practices of making Sámi programmes inevitably result in a linguistically diverse environment, which can challenge official language policy. In all three cases, we see a (modernist) emphasis on uniformity and homogeneity, meeting a sociolinguistic reality which imposes diversity and multiplicity. The result is a shift in focus, from multilingualism to heteroglossia. And, like in Lane's Norwegian case, we clearly see how media contexts enable various forms of hegemonic and anti-hegemonic language policing.

This affordance of media to organise policing procedures is clearly illustrated in the third paper in the volume, by Jan Blommaert. The shift from policy to wider issues of normativity is also central to this paper. Blommaert examines internetbased American accent training courses, a new kind of 'correspondence course' that aims at the heart of globalisation processes: providers cater for transnational elites and, often specifically, for people aspiring to work in international call centre industries. The providers are private actors and they operate in a non-regulated 
space of language normativity - there is no explicit language policy that governs their operations. Yet, we see that providers articulate an outspoken normativity, defining non-American accents across the board as undesirable (and hence things that one should get rid of), while in the same move defining American accent as an invisible, 'exnominated' accent, an accent which is no longer an accent. The providers, in sum, clearly impose a regime of language on their customers, driven by globalised images of success and achievement. And while prospective call centre operatives in India have learned 'English' at school, the internet courses offer them a particular sub-language register that operates on the basis of different norms than the school-based 'English' ones. They thus shape a polycentric environment, in which very different language norms are simultaneously at play.

While Blommaert is quite pessimistic with regard to the agency of American accent learners, the final paper by Sirpa Leppänen and Arja Piirainen-Marsh offers a more optimistic view of agency in the field of language policing. Their paper places the study of language policy in the context of discursive processes through which individual media consumers interact with the global media industry of electronic games. These processes, involving both interactional and textual activity, are seen as sites for creating and negotiating_-policing_norms for language choice and use. Language policy is viewed as emergent and situated, linked to the normative orders produced, maintained and reformulated by gamers in their discursive activities in the context of collaborative game play and fan fiction. Gaming provides an interesting site for investigating policing, because it is not regulated by a monocentric language policy, but instead opens up multiple and heterogeneous social spaces in which gamers as social actors can participate in diverse local and translocal communities shaped by covert and overt norms established, maintained and reformulated by their members' own actions. The paper investigates how young Finnish gamers draw upon English - the language of global youth media-as a locally available resource in collaborative game playing as a mundane social activity, and in internet-based fan fiction writing by game fans. More specifically, it analyses repetition and imitation of voices in the game as a verbal and embodied practice through which players manage and make sense of the game, and as a textual practice through which fan fiction writers intervene in and reinterpret game narratives, thus creating and monitoring a shared order of normativity in specific gaming contexts.

The different papers in this volume cover a variety of actors, ranging from highly solidified state institutions to young people playing games and writing fan fiction. These actors-this is a crucial point - never operate alone, but always have to work in a polycentric environment in which different norms need to be negotiated and balanced against each other. Thus, we see how the Norwegian Language Council faces old and new media in a debate over identity; minority media institutions have to confront other pluriform actors in society; Internet providers operate in a fuzzy and contradictory relationship with formal English-teaching institutions; and gamers interact with established youth culture discourses. This space is dynamic and unstable, and dichotomies such as top-down versus bottom-up may not capture fully the dynamics of the processes of normativity and normalisation that operate there. The multiplicity of actors and actions is what compels us to explore a 
different conceptual apparatus, engaging productively and constructively with recent contributions to an emerging research paradigm that explores language policy as an evolving phenomenon shaped and reshaped by discursive practices, which in turn are embedded in the multiple contextual and semiotic resources available in specific social activities and environments (cf. e.g. Ricento 2006; Shohamy 2006). Attention to the actions and actors involved in processes of language policing, is, we believe, a step into this direction.

Open Access This article is distributed under the terms of the Creative Commons Attribution Noncommercial License which permits any noncommercial use, distribution, and reproduction in any medium, provided the original author(s) and source are credited.

\section{References}

Bauman, Z. (1986). Modernity and ambivalence. Cambridge: Polity Press.

Bauman, R., \& Briggs, C. (2003). Voices of modernity. Cambridge: Cambridge University Press.

Blommaert, J. (Ed.). (1999). Language ideological debates. Berlin: Mouton de Gruyter.

Foucault, M. (2007). Security, territory, population. London: Palgrave.

Ricento, T. (Ed.). (2000). Ideology, politics, and language politics: Focus on english. Amsterdam: John Benjamins.

Ricento, T. (Ed.). (2006). An introduction to language policy, theory and practice. Oxford: Blackwell. Shohamy, E. (2006). Language policy: Hidden agendas and new approaches. London: Routledge.

Wright, S. (2004). Language policy and language planning: From nationalism to globalisation. Basingstoke and New York: Palgrave MacMillan. 